\title{
Geriatric Dentistry: A Review
}

\author{
Dhankar $\mathrm{K}^{1}$, Ingle NA ${ }^{2}$, Chaudhary $\mathrm{A}^{3}$, Kaur $\mathbf{N}^{4}$
}

\begin{abstract}
Education in geriatric medicine is in its infancy in India and geriatric dentistry is nonexistent. Poor oral health is linked to serious systemic diseases such as cardiovascular diseases and stroke. Edentulousness and paucity of prosthodontic rehabilitation prevent the elderly from choosing food that they like and deny them the pleasure of eating, which is essential for a feeling of wellbeing. Oral mucosal diseases and lesions are common in elderly people. Many older adults have pigmented and benign soft-tissue and hard-tissue conditions. Lichenoid mucosal lesions can also be caused by a variety of medications commonly prescribed in older patients. The prevalence of leukoplakia and lichen planus in older people ranges from 1.0 to $4.8 \%$ and 1.1 to $6.6 \%$, respectively. Fifty percent of zoster patients over 60 years of age will develop postherpetic neuralgia that may persist for months or even years.Root surface caries result from an age-related condition that develops on cementum following gingival recession or as an extension of existing coronal caries onto the root surface coronal caries are also quite prevalent among older persons. A recent survey of 65-74year-old in Madagascar observed that the mean number of DMFT was 20.2. In China, second national oral health survey revealed that the mean number of decayed and filled teeth was 2.5 at old age, and study in India confirmed this figure observed in China, the mean number of decayed teeth being 2.5. Denture stomatitis is a common oral mucosal lesion of clinical importance in old-age populations. The prevalence rate of stomatitis is reported within the range of $11-67 \%$ in complete denture wearers. Other major denture-related lesions include denture hyperplasia and traumatic ulcer; their prevalence rates in old-age denture wearers range from 4 to $26 \%$.
\end{abstract}

Keywords: Geriatric population, Quality of life, Prosthetic need, Denture satisfaction

${ }^{1}$ Senior Lecturer

Department of Public Health Dentistry

School of Dental Sciences, Sharda University,

Greater Noida, UP, INDIA

2 Professor \& Head

Department of Public Health Dentistry

Kanti Devi Dental College and Hospital,

Mathura, UP, INDIA

${ }^{3}$ Senior Lecturer

Department of Public Health Dentistry

School of Dental Sciences, Sharda University,

Greater Noida, UP, INDIA

${ }^{4}$ Senior Lecturer

Department of Public Health Dentistry

Kanti Devi Dental College and Hospital,

Mathura, UP, INDIA

\section{Contact Author \\ Dr Kuldeep Dhanker dr.kuldeepdhanker@gmail.com}

J Oral Health Comm Dent 2013;7(3)170-173

\section{INTRODUCTION}

nowledge of human behaviour
is a requirement in all branches
of health and oral health especially public health dentistry and pediatric dentistry. As people live longer they become elder. The physiological processes of ageing and the gradual diminution in acuity of the five senses are facts, but the rate at which they occur shows great variation (1).

The global population is increasing at an annual rate of $1.2 \%$, while the population of those 65 years or older is increasing at a rate of $2.3 \%$. About 600 million people are currently aged 60 years or older, and this number is expected to double up by 2025. By 2050, there will be 2 billion older people, $80 \%$ of them living in developing countries (2).

The growing proportion of the elderly is attributed mainly to the decrease in mortality rates among older people and overall decline in birth rates. The World Oral Health Report 2003 emphasizes that oral diseases are age related, that the risk factors for chronic disease are common to most oral diseases, and that oral health is an integral part of general health and an important component of Quality of life (QOL). Chronic diseases are more prevalent in the older population, whose age-associated physiological changes may deprive them of their mobility and independence (2).

India is a vast country with a population of more than 1.2 billion. Of this, people older than 60 years constitute $7.6 \%$, which in actual number is 76 million. Incidence of oral cancer, which is considered an old age disease, is highest in India. Preventive dental care is almost nonexistent to the rural masses and very limited in urban. Above all, there is no orientation of dental 
graduates towards the special needs of geriatric population. Recommendation includes education on geriatric population, diploma, certificate in geriatric dentistry, provision of various preventive and curative treatments for various oral diseases of the elderly (3).

However, the link among oral health, systemic disease, and quality of life in the elderly needs to be better-defined. There is some evidence in the literature that indicates that coronal and root caries appear to be major health problems for the elderly (4).

Developing countries elders who are currently most in need of oral care are the poor and disabled. Geriatric dentistry should receive increased emphasis in the nation's dental schools, specifically in predoctoral dental curricula (5).

Fortunately, loss of teeth because of periodontitis is unusual among elderly people, no matter how frail, and a recent systematic review of existing evidence concluded that the connections between poor oral hygiene, periodontitis and tooth loss are very uncertain. Nonetheless, plaque continues to cause chronic marginal gingivitis, which is almost endemic in this population (6).

There is a paucity of basic data on oral health care and knowledge and perception and past dental experience of elderly in India.

By keeping these points in mind and with the help of various literatures a review is being made to throw some light on the following objectives.

- To evaluate the need of geriatric dentistry in India

- To assess dental health of elderly population and evaluate their attitude regarding dental health and disease.

\section{HISTORY AND NEED FOR SPECIAL- ISED CARE FOR GERIATRIC POPU- LATION IN INDIA}

In 1972, a World Health Organization (WHO) commission concluded that "education is inextricably interwoven with the health services system." This statement cannot have more direct implication than in the field of geriatric dentistry. Patient and community health outcome is shown to be directly related to the education of health practitioners. Quality of health care by graduates, especially to the elderly, is likely to be related to their education. Without firsthand experience of growing old and adequate knowledge of social, psychological, and economic aspects of growing old, the dentist will be prone to errors, especially of omission. It has been reported that the attitude of dental students towards elderly patients is more or less neutral when regular dental curriculum is followed. Unless education in care of the elderly was included, it is difficult to change students' attitude from neutral to positive for better health care delivery(1).

A few unique facts regarding the elderly population in India include the following:

- The rate of growth of the elderly population is faster than that of the general population.

- There is a larger proportion of women among the elderly $(52 \%$ of the $>60$ years and $>55 \%$ of the $>80$ years age groups).

- Eighty per cent of the elderly population resides in rural areas.

- Nine per cent of the elderly live alone or with persons other than their immediate family members.

- Nearly $75 \%$ of the elderly are economically dependent, with little difference between the urban and rural elderly.

- Three-fourths of the dependent elderly population is supported by their own family members.

- Thirty per cent of the elderly are below the poverty line. Only 53.5\% of the urban elderly and $37 \%$ of the rural elderly possess some kind of financial assets.

- Only $28 \%$ of the elderly population is literate (low compared with the national average).

In India, the elderly population suffers from numerous dental and oral health problems. The Government of India announced a National Policy for Older Persons (NPOP) in January 1999, which aimed to provide financial, food, health and shelter security. Several schemes such as provident funds, pensions and gratuity, etc. provide financial security in old age. However, there is no social and financial security plan for workers in unorganized sectors such as farm labourers, daily wage earners, etc. The National Old Age Pension Scheme covers only $1 \%$ of the elderly population and the amount given is a paltry Rs $75-150$ per month (3).

According to estimates, about $50 \%$ of schoolchildren are suffering from Dental caries and more than $90 \%$ of adults are having periodontal diseases. The use of tobacco products, smoking or smokeless form, are widely prevalent in our country. Hence, oral pre-cancers and cancers are emerging as major threat to younger people and are increasing to alarming proportion in India(7).

Among the elderly in 65-74 yrs age group, the DCI survey reported caries prevalence to be about $70 \%$ while the multi-centric oral health survey reported it to be 51-95\% in various states. Higher prevalence (100\%) of gingival bleeding in 65-74 years was reported from few states (Orissa, Rajasthan) in the multi-centric oral health survey.

The loss of attachment ( $3 \mathrm{~mm}$ or more) was $96 \%$ in 65-74 years old in Maharashtra in the multi-centric oral health survey. The DCI study has reported prevalence of loss of attachment for 65-74 years as $60.7 \%$, which is comparatively lower than found in the multi-centric oral health survey. As per the multi-centric oral health survey complete edentulousness was reported to be maximum (18.5\%) in Delhi, which was comparable with the DCI data, which reported complete edentulousness in 19.9\%. The lowest level of edentulousness was reported from Arunachal Pradesh in only 16 subjects $(1.0 \%)$. Of $18.5 \%$ edentulous subjects in Delhi, about half of them $(9.8 \%)$ were using complete dentures while there were no denture wearers in Arunachal Pradesh. In Rajasthan, though the prevalence of complete edentulousness was $10 \%$, only $0.1 \%$ had complete dentures (8). The interrelationship between oral health 
and general health is particularly pronounced among older people. Poor oral health can increase the risks to general health and with compromised chewing and eating abilities, affect nutritional intake. Similarly, systemic diseases and/or the adverse side effects of their treatments can lead to increased risk of oral diseases, dry mouth and altered sense of taste and smell. The high prevalence of multimedication therapies in advanced age may further complicate the impact on oral health and oral health care (9).

The predominant oral health problems of the elderly include dental caries, periodontal disease, dry mouth (xerostomia), tooth wear and oral cancer. Recurrent caries around failing restorations, cervical caries (around the neck of the tooth) or root caries are the most common dental caries in the elderly. The prevalence of periodontal disease appears to increase with age, which may reflect an accumulation of disease over time rather than enhanced susceptibility. The number of teeth that need to be extracted due to periodontal disease increases with age. The progressive impact of smoking and drinking on the development of soft tissue lesions is more apparent in older adults, and the prevalence of oral cancer increases with age (10).

Patients with oral mucosa diseases suffer from severe and life threatening symptoms, preventing them from eating and drinking, and influencing daily life in many ways. Oral health problems can result in pain and discomfort and can lead to problems in eating, interpersonal relationships, appearance and an individual's positive self-image.

Llewellyn and Warnakulasuriya evaluated stomatological diseases (keratosis, ulcers, lichen planus, candidiasis, dry mouth, burning mouth, temporomandibular disorders and pain) using the OHIP-14, finding that diseases of the oral mucosa can have a serious impact on the patients' oral quality of life. Hegarthy et al. found that increase in pain evaluated by VAS score was associated with poor oral health-related quality of life in patients with lichen planus. Pain is an important factor in limiting oral and other everyday functions in patients. Tambolli S et al. in 2009 studied the quality of life and psychological problems in patients with oral mucosa disease, finding that oral mucosal conditions radically affected HRQoL and were accompanied by a very high frequency of psychological problems. Mumcu et al. Observed worse oral health-related quality of life in patients with Behçet's disease and recurrent aphthous stomatitis, and in patients with active oral ulcers compared with ulcer-free ones(11).

\section{STRATEGIES TOWARDS IMPROVING} ORAL HEALTH OF OLDER PEOPLE

Globally, important mechanisms for better oral health would relate to strengthening oral health policy development; national capacity building within oral health care for the underserved; education and training for service and care for the elderly, and research for oral health. However, the challenges vary from country to country and region to region; the differences are particularly notable between developed and developing countries (9).

\section{ORAL HEALTH POLICY}

As emphasized in the World Oral Health Report 2003, WHO sees oral health as integral to general health and as a determinant for quality of life? The interrelationship between oral health and general health is particularly pronounced among older people primarily because several oral diseases have risk factors in common with chronic diseases. Today, few countries have clearly stated policies and goals specifically for oral health promotion and oral health care for older people. Generally speaking, oral health policies and programmes should be an integral part of national and community health programmes. Thus, in many countries - developing and developed strengthened analysis for policy and analysis of policy are urgently needed for advocacy, legislation, goal setting, and design of public oral health programmes for old-age persons(9).

Oral health planners and administrators are encouraged to use the common risk factors approach to integrate interventions for oral health among older adults into general health programmes. A benefit of this approach is the focus on improving health conditions for the whole population as well as high risk groups such as older adults, thereby alleviating inequities(9).

\section{FACTORS INFLUENCING EATING ABILITY OF ELDERS}

Ronald J. Hunt carried out the study as there was need for data on edentulism and oral health problems in free living population of elderly people so that more definitive conclusion can be drawn for planning and policy purposes in Iowa countries. The study concluded that elderly people tend to underestimate their treatment needs. It may be that these people expect to have some problem with their dentures and accept these problems without feeling a need to seek treatment (12).

R. J. Hawkins carried out the study to determine the relative contribution of dental caries and periodontal disease as reasons for indicating tooth extraction among nursing home residents and independently living adults in Canada. This study concluded that tooth extraction in elderly population was more due to caries as a major reason. Whereas, both periodontal condition and caries continue to be the causative factor for the tooth loss, as periodontitis contributes in tooth loss affecting more than $20 \%$ of older adults (13).

\section{PROSTHETIC NEED AND DENTURE SATISFACTION}

Miyazaki H. carried out a study to assess the oral health condition and denture treatment needs in institutionalised elderly people in Japan. The study concluded that the dentition were in terminal stage with regard to oral diseases among institutionalised elderly people. The higher level of untreated teeth and denture treatment need and poor oral hygiene were found in elderly people with poor general health than in those with better health. A two way system for oral health care should be planned; i.e. one is the provision of oral care services for elderly population, second a program for oral disease prevention in younger generation (14). 
A Mersel carried out a study to evaluate the extent of denture satisfaction in Israeli elderly one year or more after prosthesis placement and explore the effect of age, gender, marital status and medical status upon denture acceptance in Israeli. The study concluded that Israeli elders were mostly satisfied with their denture after $1 \mathrm{yr}$ of use. The denture satisfaction in Israeli elderly people depends on various aspects such as marital status, presence of systemic disease, immigration history, physiological disorder and chronological age. This study also made clinician to consider these variables prior to new denture fabrication in order to prognostic outcome (15).

\section{ORAL HEALTH AND QUALITYOF LIFE}

A. J. Hassel carried out a study to obtain information about the subjective oral health status of non clinical elderly population of urban regions of Germany, one in east and one in west by using OHIP14 and for first time the GOHAI and further more to compare the results obtained by use of both instruments in Germany. The study concluded that GOHAI score for this randomly chosen non clinical group enable comparison with scores measured in future. When focusing more on subjective oral health, reflecting minor clinical changes or assessing more immediate functional aspects, the GOHAI seems more appropriate in this collectively. When researchers are additionally e.g. interested in these single aspects, for e.g. happiness with appearance, the GOHAI is more appropriate than the OHIP (16).

Hugo FN carried out a study to achieve objective was to evaluate if poor oral status was associated with lower ratings in WHO QOL-BREF domain i.e. physical, psychological, social relations and environ- ment. The study has random sample of 872 persons of more than $60 \mathrm{yrs}$ of age from municipality registers. The study concluded that oral states may cause suffering and impact on general QOL This study suggests that independent living older person without teeth or not satisfied with their own ability to chew food have an increase chance of reporting a poorer QOL in general as assesses with WHO QOL BREF (17).

Kim H-Y carried out a study to assess the association of chewing ability to OHRQOL measured by OHIP 14 controlling for clinical oral health status, self reported health status, demographic factors and socioeconomic condition among community dwelling and institutionalised Korean elders. The study concluded that there was highly significant association between chewing ability and OHRQOL measured by OHIP14 score, after controlling related factors. The ability to chew effectively a wide variety of food may facilitate the pleasurable sensation of foods, social context of sharing a meal with others, and health benefits of a diverse diet. Amelioration of chewing ability might independently contribute in improving OHRQOL of elders (18).

\section{REFERENCES}

1. Bertram Cohen, Thomas. Text book of "Dental Care for the Elderly ". Chapter 1; 4-28.

2. Daniel Kandelman, Poul Erik Peleison, Hiroshi Ueda. Oral health, general health and Quality of life in Older People. Spec Care Dentist 2008;28(6):224-36.

3. Shah N. Geriatric oral Health issues in India. Int Dent J 2001;51(3 suppl):21218.

4. C Meyerrowitz. Geriatric Dentistry and Preventive research and public policy (reactive paper). Adv Dent Res 1991;5: 74-77.

5. Ira B Lamster. Oral health care services for older Adults - A looming crisis.
American Journal of Public Health 2004; 94(5):79-84.

6. Michael I, Mace tee. Missing link in Oral health Care for frail elderly people. J Can Dent Association 2006;75(5):421-25.

7. James L. Leaks. History of Dental programs for older adults. J Can Dent Assoc 2000;66:316-19.

8. Nassem Shah. Geriatric dentistry: The need for new speciality in India. National Medical Journal of India 2005;18(1):3738.

9. Naseem Shah. Teaching, learning and assessment in Geriatric dentistry. Journal of Dental Education 2005;74(1): 20-28.

10. Murray JJ. Textbook of Prevention of Oral disease, Chapter - Prevention in the aging dentition, Fourth edition, CBE Oxford University Press.

11. Jonathan A. Ship, Textbook of Diagnosis and treatment, Chapter - Geriatrics, Tenth edition 605-621.

12. Ronald J. Hunt. Edentulism and Oral Health Problems among Elderly Rural lowans: The lowa 65+ Rural Health Study. AJPH 1981;75(10):210-218.

13. RJ Hawkins, PA Main, Locker D. The normative need for tooth extractions in older adults in Ontario, Canada. Gerodontology 1998;14(2):76-87.

14. Miyazaki H, Shirahatna R, Ohlarri I, Shimada N, Takehara T. Oral health conditions and denture treatment needs in institutionalized elderly people in Japan. Community Dent Oral Fpidemiol 1992;20:297-301.

15. Mersel A, Babayof I, Bcrkey D, Mann J. Variables affecting denture satisfaction in Tsraeli elderlyia one year follow-up. Gerodontology 1995;12(2):89-94.

16. Hassel AJ, Steuker B, Rolko C. Oral healthrelated quality of life of elderly Germans - comparison of GOHAI and OHIP-14. Gerodontology 2005;23:69-76.

17. Hugo FN, Hilgert JB. Oral status and its association with general quality of life in older independent-living south-Brazilians. Community Dent Oral Epidemiol 2009;37:231-240.

18. Kim HY, Jang MS, Chung CP, Paik DI, Park YD, Patton LL, et al. Chewing function impacts oral health-related quality of life among institutionalized and communitydwelling Korean elders. Community Dent Oral Epidemiol 2009;37(5):468-76. 